\title{
Concurrent Designs of Surface Permanent Magnet Machines for Self-Sensing Position Estimation and Power-Conversion
}

\author{
Shih-Chin Yang $^{* a)}$ Non-member, Robert D. Lorenz ${ }^{* *}$ Non-member
}

(Manuscript received Dec. 23, 2011, revised March 6, 2012)

\begin{abstract}
This paper presents the concurrent designs of surface permanent magnet (SPM) machines for saliency-tracking selfsensing position estimation and power-conversion. Three SPM machine design approaches are discussed from the perspectives of position estimation and power-conversion. Finite element analysis (FEA) is mainly used in this study to obtain an insight into the magnetic behaviors in SPM machines. With the appropriate design modification, SPM machines can effectively increase the saliency for the closed-loop control while preserving their power-conversion capabilities.
\end{abstract}

Keywords: self-sensing machine, sensorless control

\section{Introduction}

Closed-loop control by using a machine itself as a position sensor (self-sensing) has been a popular research for these two decades ${ }^{(1)-(5)}$. Not only the low cost but also the high reliability can be achieved by removing the separate sensor and cable in the machine. It is important to develop a stiff closedloop self-sensing machine drive from the measurement of terminal properties, i.e. current sensor or voltage sensor signals.

Closed-loop control of self-sensing machine can be achieved by the tracking of back electromotive-force $(\mathrm{EMF})^{(3)(4)}$ or by the tracking of spatial saliency with persistent excitation $^{(1)(2)(5)}$. For back EMF tracking, the spatial distribution in the back EMF voltage is used to estimate the position and speed. Because back EMF voltage is obtained from the phase voltage subtracting the estimated voltage drop across the estimated impedance, the impedance variation can degrade the EMF tracking performance. In addition, back EMF voltage is a position-dependent function since it is induced by the time derivative of the flux linkage. It is expected that the performance of back EMF tracking degrades as the speed decreases. Ultimately, the closed-loop control will fails at zero speed since there is no back EMF in the machine ${ }^{(4)}$.

Instead of back EMF, the tracking of spatial saliency has demonstrated the better closed-loop control performance down to zero speed ${ }^{(5)}$. Saliency persistent excitation is required to yield the position dependent signal. The spatial saliency can be viewed as either a change in inductance ${ }^{(1)(2)(5)}$ or resistance ${ }^{(6)(7)}$ as the rotor rotates. It is important to note that not all the machines can have sufficient spatial saliencies for tracking. For interior permanent magnet (IPM) machines, the saliency is caused by the variation of air gap permaence.

\footnotetext{
a) Correspondence to: Shih-Chin Yang. E-mail: scy@ti.com

${ }^{*}$ Texas Instruments Incorporated, Motor Laboratory Dallas, TX 75243 USA

${ }^{* *}$ University of Wisconsin-Madison, Wisconsin Electric Machines and Power Electronics Consortium

Madison, WI 53706 USA
}

Due to the considerable flux saturation in the rotors, the saliencies in IPM machines might decrease and shift as the load increases ${ }^{(8)(9)}$. Ref. (8) investigated the influence of rotor geometry on the measurement of the saliency distribution at different load conditions. Saturation of the q-axis flux, and $\mathrm{d}$ - and q-axis cross-coupling were identified as the primary issues to limit the saliency-tracking performance. Recently, a novel flux-intensified IPM machine has been introduced to achieve the reverse saliency $\left(\mathrm{L}_{\mathrm{d}}>\mathrm{L}_{\mathrm{q}}\right)^{(10)}$. This type of IPM machine shows the minor impact of the rotor saturation on the saliency-tracking as well as the power-conversion.

For induction machines, additional design modification is required to specially create the saliency for closed-loop control $^{(1)(11)-(13)}$. Several methods have been proposed to design the saliencies on the rotors of inductance machines. In general, they aim to adjust the rotor leakage flux spatially and can be classified into four types, 1) rotor tooth slot opening modification $\left.^{(1)(12)}, 2\right)$ rotor tooth depth modulation $\left.{ }^{(1)(12)}, 3\right)$ rotor tooth slot opening fill modulation ${ }^{(1)}$, and 4) rotor slot and stator slot modulation ${ }^{(11)(13)}$. Under these effects, a general design guideline regarding to the specific machine geometric feature has been proposed in Ref. (12). It is shown that the design tradeoff between the load invariant saliencies and the reduced impact on the power-conversion can be made in induction machines.

The purpose of this paper is to introduce the design methods of SPM machines for the saliency-tracking self-sensing position estimation while balancing their power-conversion capabilities. Due to the symmetric nature in SPM rotors, additional saliencies must be designed to achieve the closedloop control. Several design options ${ }^{(7)(14)(15)}$ are comparatively evaluated. FEA is used to analyze their saliency properties. It is shown that magnetic behaviors and flux characteristics are the key to design a self-sensing SPM machine. Finally, a design guideline of the self-sensing SPM machine is summarized. 


\section{Outline of Design Objectives}

Because of the symmetric feature, SPM machines have to be modified in order to utilize the saliency-tracking technique. In this section, two performance indices are introduced. They will be used to evaluate the following designed self-sensing SPM machines.

2.1 Saliency Ratio The basic idea of saliencytracking technique is to estimate the rotor position by measuring the position dependent signal reflected by the spatial inductance variation. Fig. 1 shows the spatial inductance, $\mathrm{L}_{\alpha}$, in the stationary frame., where $\Delta \mathrm{L}$ is the differential inductance and $\Sigma \mathrm{L}$ is the average inductance. Considering the inductance variation, the machine model can be expressed by (1) in the stationary frame.

$$
\begin{aligned}
\mathrm{v}_{\alpha \beta}= & \left\{\begin{array}{l}
\mathrm{v}_{\alpha} \\
\mathrm{v}_{\beta}
\end{array}\right\} \\
= & {\left[\begin{array}{cc}
\mathrm{R}_{\mathrm{s}}+\mathrm{p}\left(\Sigma \mathrm{L}-\Delta \mathrm{L} \cos \left(2 \theta_{\mathrm{e}}\right)\right) & -\mathrm{p} \Delta \mathrm{L} \sin \left(2 \theta_{\mathrm{e}}\right) \\
\mathrm{p} \Delta \mathrm{L} \sin \left(2 \theta_{\mathrm{e}}\right) & \mathrm{R}_{\mathrm{s}}+\mathrm{p}\left(\Sigma \mathrm{L}-\Delta \mathrm{L} \cos \left(2 \theta_{\mathrm{e}}\right)\right)
\end{array}\right]\left\{\begin{array}{c}
\mathrm{i}_{\alpha} \\
\mathrm{i}_{\beta}
\end{array}\right\} } \\
& +\left[\begin{array}{c}
-\omega_{\mathrm{e}} \lambda_{\mathrm{pm}} \sin \theta_{\mathrm{e}} \\
\omega_{\mathrm{e}} \lambda_{\mathrm{pm}} \cos \theta_{\mathrm{e}}
\end{array}\right] \ldots \ldots \ldots \ldots \ldots \ldots \ldots \ldots \ldots \ldots \ldots \ldots \ldots
\end{aligned}
$$

where $\mathrm{V}_{\alpha \beta}$ is the voltage in the stationary frame, $\mathrm{I}_{\alpha \beta}$ is the current in the stationary frame, $\lambda_{\mathrm{pm}}$ is the permanent magnet flux, $\theta_{\mathrm{e}}$ and $\omega_{\mathrm{e}}$ are the rotor position and speed, respectively, and $\mathrm{p}$ is equal to $\mathrm{d} / \mathrm{dt}$ for simplicity. In order to achieve the zero and low speed closed-loop control, a high frequency (HF) rotating voltage vector, $\mathrm{V}_{\alpha \beta \_\mathrm{HF}}$ in (2), with the constant amplitude can be injected. Assuming a negligible resistance voltage drop, the reflected HF current, $\mathrm{I}_{\alpha \beta_{-} \mathrm{HF}}$, can be shown in (3).

$$
\begin{aligned}
& \mathrm{V}_{\alpha \beta \_\mathrm{HF}}=\mathrm{v}_{\mathrm{c}}\left[\begin{array}{c}
\cos \left(\omega_{\mathrm{c}} \mathrm{t}\right) \\
\sin \left(\omega_{\mathrm{c}} \mathrm{t}\right)
\end{array}\right]=-\mathrm{v}_{\mathrm{c}} \mathrm{e}^{\mathrm{j} \omega_{\mathrm{c}} \mathrm{t}} \ldots \ldots \ldots \ldots \ldots \ldots \\
& \mathrm{I}_{\alpha \beta \_\mathrm{HF}}=-\mathrm{jI}_{\mathrm{p} \_\mathrm{HF}} \mathrm{e}^{\mathrm{j} \omega_{\mathrm{c}} \mathrm{t}}+\mathrm{jI}_{\mathrm{n} \_\mathrm{HF}} \mathrm{e}^{-\mathrm{j}\left(\omega_{\mathrm{c}} \mathrm{t}-2 \theta_{\mathrm{e}}\right)} \ldots \ldots \ldots \ldots \\
& \mathrm{I}_{\mathrm{p} \_\mathrm{HF}}=\frac{\mathrm{v}_{\mathrm{c}}}{\omega_{\mathrm{c}}}\left[\frac{\Sigma \mathrm{L}}{\Sigma \mathrm{L}^{2}-\Delta \mathrm{L}^{2}}\right] \approx \frac{\mathrm{v}_{\mathrm{c}}}{\Sigma \mathrm{L} \omega_{\mathrm{c}}} \ldots \ldots \ldots \ldots \ldots \\
& \mathrm{I}_{\mathrm{n} \_\mathrm{HF}}=\frac{\mathrm{v}_{\mathrm{c}}}{\omega_{\mathrm{c}}}\left[\frac{\Delta \mathrm{L}}{\Sigma \mathrm{L}^{2}-\Delta \mathrm{L}^{2}}\right] \approx \frac{\Delta \mathrm{L} \mathrm{v}_{\mathrm{c}}}{\Sigma \mathrm{L}^{2} \omega_{\mathrm{c}}} \ldots \ldots \ldots \ldots \ldots
\end{aligned}
$$

where $\mathrm{v}_{\mathrm{c}}$ and $\omega_{\mathrm{c}}$ are the amplitude and frequency of $\mathrm{V}_{\alpha \beta_{-} \mathrm{HF}}$, and $\mathrm{I}_{\mathrm{p} \_\mathrm{HF}}$ and $\mathrm{I}_{\mathrm{n}_{-} \mathrm{HF}}$ are the amplitude of positive and negative sequence current of $I_{\alpha \beta}$ HF. As seen in (3), $I_{n_{-} H F}$ is modulated by $\mathrm{e}^{-\mathrm{j}\left(\omega_{\mathrm{c}} \mathrm{t}-2 \theta_{\mathrm{e}}\right)}$ which is useful for the position estimation. Since $\mathrm{I}_{\mathrm{n}_{-} \mathrm{HF}}$ is dependent on the ratio of $\Delta \mathrm{L}$ and $\Sigma \mathrm{L}$, it is worth to define the first performance index, saliency ratio $=\Delta \mathrm{L} / \Sigma \mathrm{L}$,

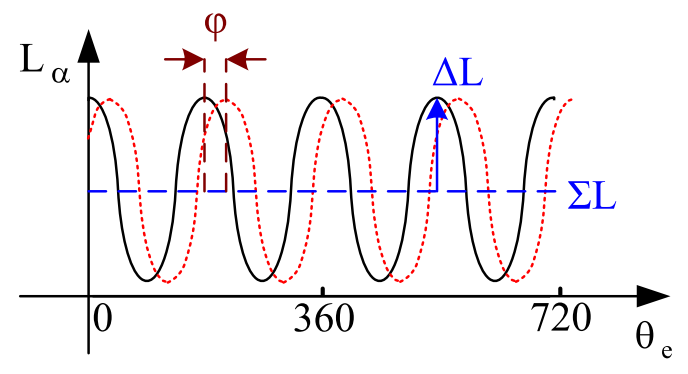

Legend: - ideal L and --- considering cross-saturation

Fig. 1. Spatial variation of stationary inductance for the evaluation of designed self-sensing SPM machines.

2.2 Saliency Angular Offset Machine d- and q-axis cross-saturation appears in virtually all forms of electric machines ${ }^{(8)}$. Considering cross-saturation, the estimated inductance position is no longer equal to the rotor position. Under this effect, the inductance matrix should be modified to agree with

$$
\begin{aligned}
\mathrm{L}_{\alpha \beta_{-} \text {sat }}= & \Sigma \mathrm{L}\left[\begin{array}{ll}
1 & 0 \\
0 & 1
\end{array}\right] \\
& +\Delta \mathrm{L}\left[\begin{array}{cc}
\cos \left[2\left(\theta_{\mathrm{e}}-\varphi\right)\right] & -\sin \left[2\left(\theta_{\mathrm{e}}-\varphi\right)\right] \\
-\sin \left[2\left(\theta_{\mathrm{e}}-\varphi\right)\right] & -\cos \left[2\left(\theta_{\mathrm{e}}-\varphi\right)\right]
\end{array}\right]
\end{aligned}
$$

where $\varphi$ is the saliency angular offset caused by dq crosssaturation. Fig. 1 shows the resulting inductance distribution considering the cross-saturation effect. It is found that cross-saturation causes a phase offset in the estimated position. This offset is proportional to $\mathrm{L}_{\mathrm{dq}} / \Delta \mathrm{L}$ and $\mathrm{L}_{\mathrm{qd}} / \Delta \mathrm{L}$, where $\mathrm{L}_{\mathrm{dq}}$ and $\mathrm{L}_{\mathrm{qd}}$ are the $\mathrm{dq}$ and qd cross-saturation-reflected inductance in the synchronous frame. Since $\varphi$ can cause the error in the position estimation, it has to be minimized in the designed self-sensing machines. Therefore, the angular offset, $\varphi$, is defined as the second performance index to evaluate the self-sensing machine.

\section{Concurrent Design of SPM Machines}

In this section, FEA is performed to investigate saliency behaviors in the designed SPM machines. Fig. 2 shows the baseline machine which is used for the design modification. The stator configuration is 9-slots having all-teeth wound concentrated windings. The rotor is a cylindrical rotor with a 8-pole ring magnet on its surface. Detailed machine characteristics are listed in Table 1, where the Ne-Fe-B material is used for the magnet and the carbon steel is selected for the stator. It is noted that these characteristics are widely used in standard SPM machines.

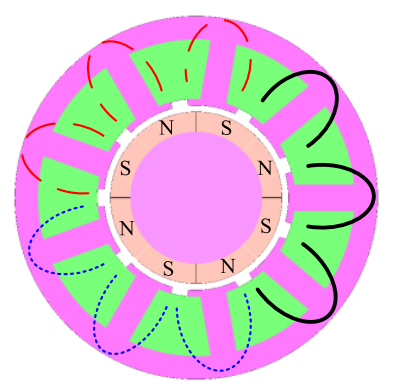

Fig. 2. Illustration of analyzed baseline SPM machine

Table 1. Characteristics of baseline machines

\begin{tabular}{cc}
\hline Characteristics & Values \\
\hline Diameter of stator/rotor & $55 \mathrm{~mm} / 26 \mathrm{~mm}$ \\
Active axial length & $20 \mathrm{~mm}$ \\
Tooth bridge height & $1 \mathrm{~mm}$ \\
Magnet height & $3 \mathrm{~mm}$ \\
Rated torque & $0.13 \mathrm{~N}-\mathrm{m}$ \\
Maximum speed & $6000 \mathrm{rpm}$ \\
Rated current & $11 \mathrm{~A}_{\text {peak }}$ \\
Rated voltage & $10 \mathrm{~V}$ \\
Torque constant & $0.012 \mathrm{~N}-\mathrm{m} / \mathrm{A}$ \\
Magnet type & $\mathrm{Ne}-\mathrm{Fe}-\mathrm{B}\left(\mathrm{B}_{\mathrm{r}}=1.1 \mathrm{~T}\right)$ \\
Magnet resistivity & $1.5 \times 10^{-6} \Omega-\mathrm{m}$ \\
Steel material (laminated) & Carbon steel $(\mathrm{SPCC})$ \\
$\Delta \mathrm{L}, \quad \Sigma$ and $\Delta \mathrm{L} / \Sigma \mathrm{L}$ (no load) & $0.396 \mu \mathrm{H}, 33 \mu \mathrm{H}$ and 0.012 \\
\hline
\end{tabular}




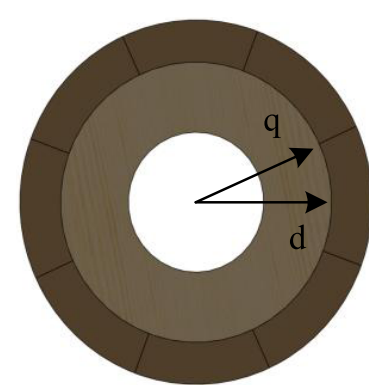

(a)

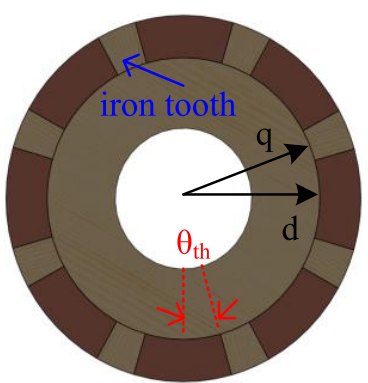

(b)
Fig. 3. SPM rotors with (a) ring magnet and (b) segment magnets and iron teeth

3.1 Asymmetric Rotor Design Since the saliency is primarily caused by the change of air gap permeance, the saliency design can try to make the SPM rotor appropriately asymmetric for the position estimation. Ref. (14) investigated several asymmetric rotors and found the rotor with the iron teeth in Fig. 3(b) can be designed for a self-sensing SPM machine. Different from the ring magnet rotor in Fig. 3(a), the iron tooth is added between two adjacent magnets along the rotor $\mathrm{q}$-axis direction.

Because the permeance of iron material is much higher than that of air, it is expected that the inductance at $\theta_{\mathrm{e}}=90^{\circ}$ is higher than the inductance at $0^{\circ}$. Under this effect, the spatial saliency can be achieved whereby $\mathrm{L}_{\mathrm{q}}>\mathrm{L}_{\mathrm{d}}$. According to Ref. (14), the corresponding saliency is dependent on the geometry of iron teeth which can be shown to be

$$
\begin{aligned}
& \mathrm{L}_{\mathrm{d} \_\mathrm{m}}=\mathrm{k}_{\mathrm{d}} \mathrm{L}_{\text {axial }} \text { and } \mathrm{L}_{\mathrm{q} \_\mathrm{m}}=\mathrm{k}_{\mathrm{q}} \mathrm{L}_{\text {axial }} \ldots \ldots \ldots \ldots \\
& \mathrm{k}_{\mathrm{d}}=1-\sin \left(\theta_{\mathrm{th}}\right)\left[1-\frac{\mathrm{g}}{\mathrm{g}+\mathrm{l}_{\mathrm{m}}}\right] \ldots \ldots \ldots \ldots \ldots \ldots \ldots \\
& \mathrm{k}_{\mathrm{q}}=\left[1-\frac{\mathrm{g}}{\mathrm{g}+\mathrm{l}_{\mathrm{m}}}\right]+\cos \left(\theta_{\mathrm{th}}\right)\left[1-\frac{\mathrm{g}}{\mathrm{g}+\mathrm{l}_{\mathrm{m}}}\right]
\end{aligned}
$$

where $\mathrm{k}_{\mathrm{d}}$ and $\mathrm{k}_{\mathrm{q}}$ are indices of $\mathrm{d}$-axis and $\mathrm{q}$-axis magnetizing inductance, $\mathrm{L}_{\mathrm{d}_{-} \mathrm{m}}$ and $\mathrm{L}_{\mathrm{q} \_\mathrm{m}}$, $\mathrm{g}$ is the physical air gap, $\mathrm{l}_{\mathrm{m}}$ is the magnet depth, $\mathrm{L}_{\text {axial }}$ is the rotor axial length, and $\theta_{\text {th }}$ is the angle covering by one half of magnet, as shown in Fig. 3(b).

The design of $\theta_{\text {th }}$ is dependent on the required saliency for the position estimation. In general, it is necessary to have the high saliency ratio for the better self-sensing performance. However, the high saliency ration leads to low $\theta_{\text {th }}$ which can cause the considerable torque ripple. The evaluation of torque performance will be discussed in the next section. In this paper, $\theta_{\mathrm{th}}$ is selected as $\theta_{\mathrm{e}}=65^{\circ}$ to achieve $\mathrm{k}_{\mathrm{q}} / \mathrm{k}_{\mathrm{d}}=3.3$. It is noted that only magnetizing inductance is considered in (8) and (9). Due to the highly leakage effect in SPMs, the actual saliency ratio will be lower than the designed one.

Based on FEA, the armature flux contour of the SPM with designed iron teeth is shown in Fig. 4, where (a) is at $\theta_{\mathrm{e}}=$ $0^{\circ}$ and (b) is at $\theta_{\mathrm{e}}=90^{\circ}$. In this analysis, the q-axis current equal to $100 \%$ rated current is applied in the FEA model. At $\theta_{\mathrm{e}}=0^{\circ}$, the majority of armature fluxes become leakage fluxes flowing across the slot opening. On the other hand at $\theta_{\mathrm{e}}=90^{\circ}$, the large portion of armature fluxes become flux linkage flowing into the iron teeth due to the relatively small air gap.

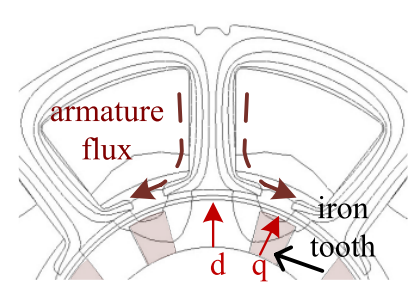

(a)

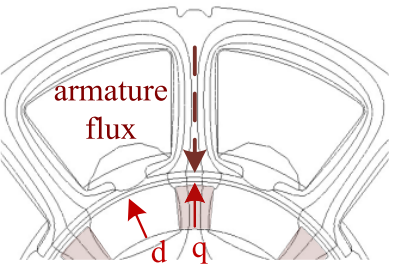

(b)
Fig. 4. Armature flux contours of SPM machine with iron teeth when the position is at (a) $\theta_{\mathrm{e}}=0^{\circ}$ and (b) $\theta_{\mathrm{e}}$ $=90^{\circ}$
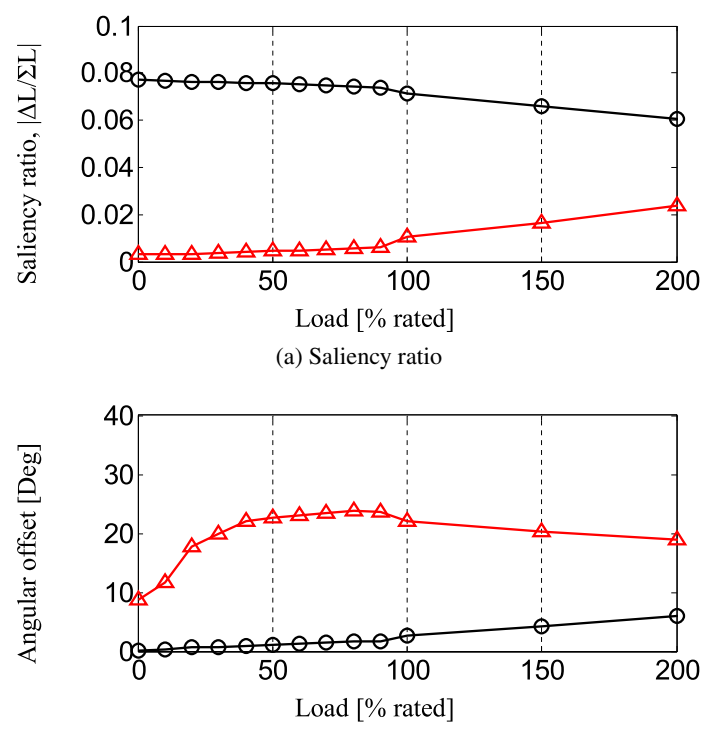

(b) Saliency angular offset

Legend: -O- iron tooth design , $-\Delta$ - ring magnet rotor (baseline)

Fig. 5. Comparison of saliency ratio and saliency angular offset between baseline and iron teeth design

Because of the higher flux linkage at $\theta_{\mathrm{e}}=90^{\circ}$, it is expected that the inductance is increased at this position. However, it is important to note that the iron tooth design results in the saliency whereby $\mathrm{L}_{\mathrm{q}}>\mathrm{L}_{\mathrm{d}}$. Due to the flux saturation, $\mathrm{L}_{\mathrm{q}}$ might reduce as the rated current (q-axis current) increases. In contrast, $\mathrm{L}_{\mathrm{d}}$ should be approximately the same under different load operation. Thus, this load dependent property can result in the degraded saliency-tracking performance at high load condition.

Fig. 5 shows the comparison of (a) saliency ratio, $\Delta \mathrm{L} / \Sigma \mathrm{L}$, and (b) the saliency angular offset, $\varphi$, versus load for SPMs with the iron tooth designed and the ring magnet rotor. For partial load operation, $\Delta \mathrm{L} / \Sigma \mathrm{L}$ can greatly increase in the machine with the iron tooth design. In addition, $\varphi$ in the designed machine is below 10 electric degree even for high load operation. Although $\Delta \mathrm{L} / \Sigma \mathrm{L}$ and $\varphi$ both degrade as load increases, the load dependence on the designed saliency is still moderate comparing to the standard IPM investigated in Ref. (8). Therefore, it is concluded the asymmetric iron tooth design can effectively add spatial saliency to SPM machines for the position estimation. A key issue on this design might be the considerable torque ripple due to the asymmetric rotor. It will be evaluated in the next section by comparing to the following saturation-induced saliency design.

3.2 Leakage Flux Saturation-induced Saliency Design In SPM machines, the saturation occurs due to the steel 


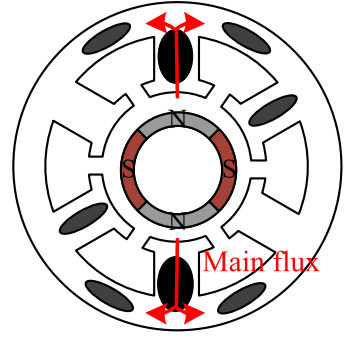

(a) Stator yoke and tooth (b) Tooth tip bridge

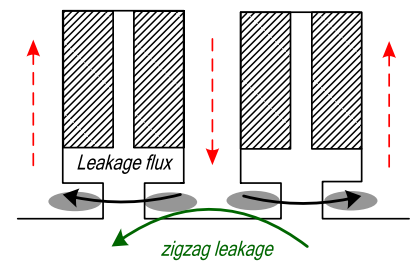

Fig. 6. Illustration of steel saturation in stator yoke and tooth, and tooth tip bridge

material in their stators. The steel saturation can result in the reduced magnitude of armature flux in the stator yoke and tooth, as shown in Fig. 6(a), and the tooth tip bridge in Fig. 6(b). In general, the yoke and tooth saturation causes the flux and inductance loss in the $\mathrm{d}$-axis because this saturation is primarily induced by the flux linkage from the magnet. In contrast, the tooth tip saturation appears due to the slot leakage flux penetrating from one tooth to another or due to the magnet zigzag leakage flux. Tooth tip saturation results in the reduced inductance in q-axis if the saturation is dominant by the zigzag leakage flux ${ }^{(15)}$.

It is noted that the saturation-induced saliency is highly dependent on the machine geometries and material properties.

When the tooth and yoke saturation is dominant in a SPM machine, $\mathrm{L}_{\mathrm{d}}$ is reduced resulting in the saliency with $\mathrm{L}_{\mathrm{q}}>\mathrm{L}_{\mathrm{d}}$. In contrast, when the tooth tip saturation is greater than the tooth and yoke saturation, the reverse saliency with $\mathrm{L}_{\mathrm{d}}>\mathrm{L}_{\mathrm{q}}$ can achieve in a SPM machine. For SPM machines, the daxis current is zero since the reluctance torque can be neglected. As load increases, q-axis current continuously increases leading to the saturation in $\mathrm{L}_{\mathrm{q}}$. Under this effect, the saliency between $\mathrm{L}_{\mathrm{q}}>\mathrm{L}_{\mathrm{d}}$ and $\mathrm{L}_{\mathrm{d}}>\mathrm{L}_{\mathrm{q}}$ can have the very different performance for the self-sensing estimation.

In Ref. (16), two SPM machines with different saliency properties, i.e. $\mathrm{L}_{\mathrm{q}}>\mathrm{L}_{\mathrm{d}}$ and $\mathrm{L}_{\mathrm{d}}>\mathrm{L}_{\mathrm{q}}$, are comparatively evaluated. It has been concluded that the reverse saliency with $\mathrm{L}_{\mathrm{d}}>\mathrm{L}_{\mathrm{q}}$ has the minor impact on the $\mathrm{L}_{\mathrm{q}}$ saturation which is the useful saliency for the position estimation. More importantly, the zigzag leakage flux saturation is the key to achieve the reverse saliency with $\mathrm{L}_{\mathrm{d}}>\mathrm{L}_{\mathrm{q}}$. In this paper, the design modification to create this reverse saliency in the baseline machine is addressed. By modulating the geometry of the tooth bridge height, the reverse saliency is increased without the need of any asymmetric rotor design.

Based on FEA, the zigzag leakage fluxes of the baseline machine at four different rotor positions are shown in Fig. 7. It is found that the zigzag flux changes as rotor rotates and increases from the position (a) $\theta_{\mathrm{e}}=0^{\circ}$ to (d) $\theta_{\mathrm{e}}=90^{\circ}$. This result demonstrates that the magnitude of zigzag flux is position dependent. The influence of zigzag flux in a machine appears in the permeance variation of equivalent air gap due to the change of tooth tip saturation.

It is noteworthy that not all SPM machines can have enough zigzag flux saturation-induced saliency for tracking. This section presents the design guidance to effectively increase the zigzag saturation-induced saliency in the baseline machine.

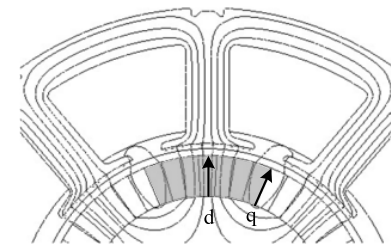

(a)

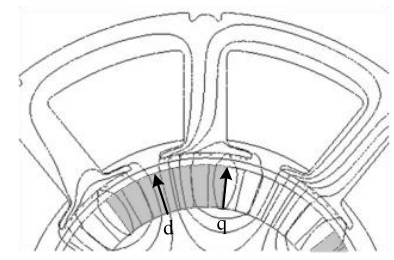

(c)

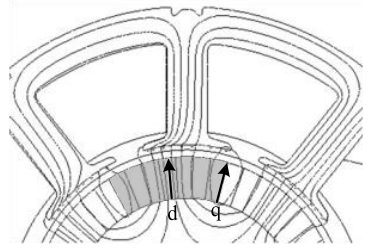

(b)

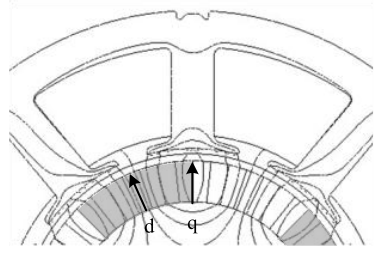

(d)
Fig. 7. Zigzag leakage flux calculated by FEA (no load condition): (a) $\theta_{\mathrm{e}}=0^{\circ}$ (no zigzag flux), (b) $\theta_{\mathrm{e}}=30^{\circ}$, (c) $\theta_{\mathrm{e}}$ $=60^{\circ}$ and $(\mathrm{d}) \theta_{\mathrm{e}}=90^{\circ}$ (peak zigzag leakage flux)

Table 2. Comparison of SPM machines with different slot-pole combinations (bridge height $=0.6 \mathrm{~mm}$ )

\begin{tabular}{cccc}
\hline Different slot-pole combinations & $\Sigma \mathrm{L}(\mu \mathrm{H})$ & $\Delta \mathrm{L}(\mu \mathrm{H})$ & $\Delta \mathrm{L} / \Sigma \mathrm{L}$ \\
\hline 12-slot-10-pole & 36.06 & 1.60 & 0.044 \\
9-solt-8-pole & 36.57 & 1.64 & 0.045 \\
12-slot-8-pole & 31.65 & 1.18 & 0.037 \\
\hline
\end{tabular}

\section{A. Design with similar numbers of slots and poles}

Based on the zigzag flux distribution in Fig. 7, it is seen that zigzag fluxes are associate with the leakage fluxes shortcircuit by two poles. As a result, increasing the pole number, $\mathrm{N}_{\mathrm{p}}$, is helpful to increase the zigzag flux. In general, SPM machines with concentrated windings have a higher $N_{p}$ than those with distributed windings if the slot number, $\mathrm{N}_{\mathrm{s}}$, is fixed. SPM machines can have the highest $\mathrm{N}_{\mathrm{p}}$ when the numbers of slots and poles follow (6).

$$
\mathrm{N}_{\mathrm{s}}=\mathrm{N}_{\mathrm{p}} \pm 2 \text { or } \quad \mathrm{N}_{\mathrm{s}}=\mathrm{N}_{\mathrm{p}} \pm 1 \cdots
$$

To validate this result, FEA models with three different slot-pole combinations were made in Table 2. It is noted that the geometric features are all the same and all-teethwound concentrated windings are used in these three machines. Suitability for self-sensing estimation is evaluated by comparing their saliency ratio, $\Delta \mathrm{L} / \Sigma \mathrm{L}$. It is found that SPM machines whose slot-pole combinations follow (6) result in higher $\Delta \mathrm{L} / \Sigma \mathrm{L}$. This result is concluded that the slot-pole design in (6) is an appropriate criterion to increase the zigzag flux saturation-induced saliency.

\section{B. Tooth bridge height modification}

In addition to increasing the magnitude of zigzag flux, it is also possible to moderately increase the saturation area in the tooth tip bridge, as shown in Fig. 8. Assuming the negligible fringing effect, the zigzag flux would flow straightly across the air gap into the tooth tip bridge. As a result, the zigzag flux induced saturation is dependent on the geometric feature of tooth bridge. The zigzag saturation condition can be increased by reducing the bridge height, $\mathrm{d}_{\mathrm{bh}}$, of baseline SPM machine. Since the symmetric rotor is still maintained in the machine, this saliency design should have the minor impact on the power-conversion, i.e. torque ripple.

Fig. 9 shows the saliency ratio versus tooth bridge height 


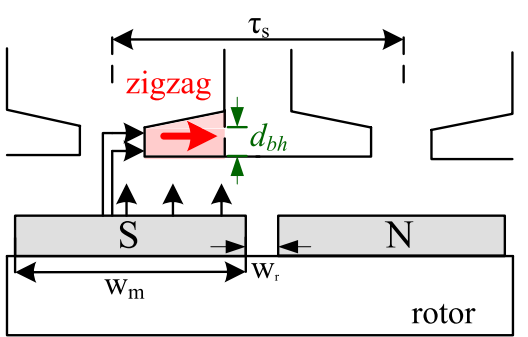

Fig. 8. Illustration of zigzag flux direction in the tooth tip

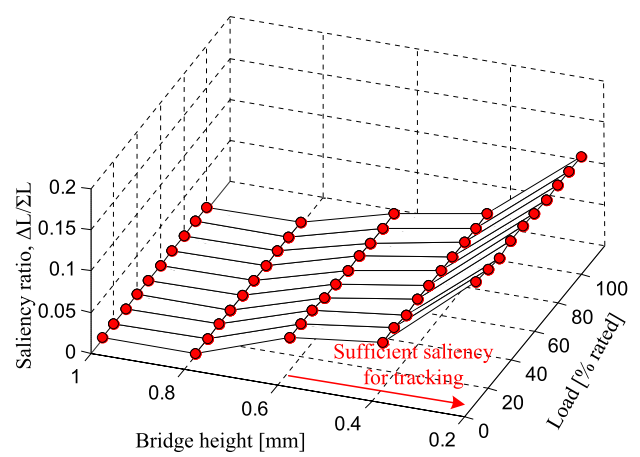

Fig. 9. Saliency ratio versus the tooth bridge height for the SPM machine with tooth bridge height modification

at different load conditions for the SPM machine shown in Fig. 2. The bridge height is $1 \mathrm{~mm}(1 \cdot \mathrm{g})$ for the baseline machine to reduce the tooth tip saturation. However, for the purpose of self-sensing machine design, it is necessary to reduce $\mathrm{d}_{\mathrm{bh}}$ for better saliency-tracking performance. As shown in Fig. 9, $\mathrm{d}_{\mathrm{bh}}$ at $0.6 \mathrm{~mm}(0.6 \mathrm{~g})$ can result in $\Delta \mathrm{L} / \Sigma \mathrm{L}=0.05$ approximately at no load condition. This increased $\Delta \mathrm{L} / \Sigma \mathrm{L}$ can be useful for the position estimation. Most importantly, die to the reversal saliency property in the zigzag flux saturation, $\Delta \mathrm{L} / \Sigma \mathrm{L}$ further increases as load increases.

The saliency ratio and angular offset as a function of load are compared in two SPM machines with the modified bridge height $\left(\mathrm{d}_{\mathrm{bh}}=0.6 \cdot \mathrm{g}\right)$ and baseline $\left(\mathrm{d}_{\mathrm{bh}}=0.8 \cdot \mathrm{g}\right)$, as shown in Fig. 10. It is found that $\Delta \mathrm{L} / \Sigma \mathrm{L}$ greatly increases for the SPM with reduced $\mathrm{d}_{\mathrm{bh}}$. More importantly, the saliency angular offset in the modified SPM is lower than that in the baseline machine. Different from the prior rotor iron tooth design, the zigzag flux saturation results in the reverse saliency with $\mathrm{L}_{\mathrm{d}}>\mathrm{L}_{\mathrm{q}}$ which can maintain the saliency ratio even at high load condition. Therefore, it is concluded that the SPM machine with the zigzag saturation-induced saliency can achieve the sufficient position dependent signal for the closed-loop control.

3.3 Loss-reflected Asymmetric Resistance Instead of the spatial variation in the inductance, the iron and magnet losses might have the spatial information in SPM machines. By injecting a HF voltage, these losses are enhanced which is sufficient for the position estimation. As mentioned in Ref. (7), the variation of HF losses can be achieved due to the change of HF flux distributions as the rotor rotates. Since HF losses can appear in all SPM machines, the loss-reflected asymmetric resistance might be measurable in general SPM machines without special saliency design. This section will address the property of HF losses in the baseline machine.

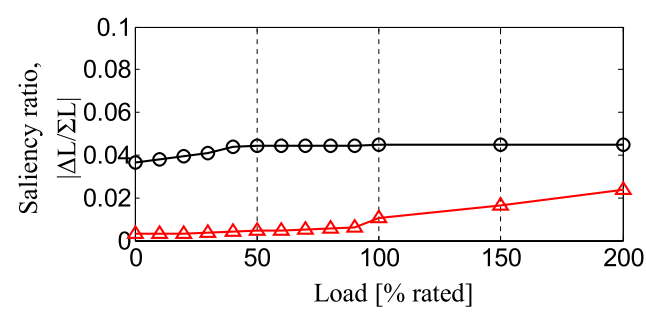

(a) Saliency ratio

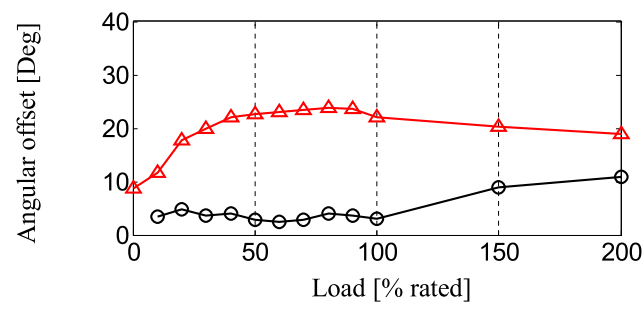

(b) Saliency angular offset

Legend: -O- modified bridge height $\left(\mathrm{d}_{\mathrm{bh}}=0.6 \cdot \mathrm{g}\right),-\Delta$ - baseline $\left(\mathrm{d}_{\mathrm{bh}}=0.8 \cdot \mathrm{g}\right)$

Fig. 10. Comparison of saliency ratio and saliency angular offset between baseline and bridge height modification

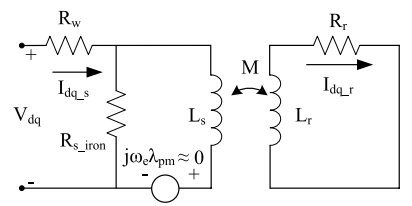

(a)

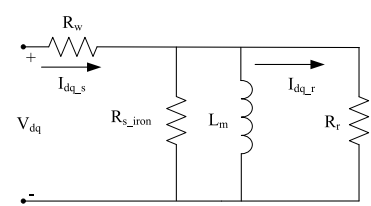

(b)
Fig. 11. HF equivalent circuit in the synchronous frame considering the iron and magnet losses: (a) normal and (b) simplified equivalent circuit

In SPM machines, HF losses, especially eddy-current losses, can occur in both stator and rotor since the superimposed frequency is sufficiently higher than the fundamental frequency. Considering the eddy-current losses in the rotor, the mutual coupling between stator and rotor flux appears. Fig. 11 (a) shows the HF equivalent circuit in the rotorreferred synchronous frame. In this figure, a mutual coupling between stator equivalent inductance, $\mathrm{L}_{\mathrm{s}}$, and $\mathrm{HF}$ rotor eddycurrent-reflected inductance, $\mathrm{L}_{\mathrm{r}}$, is shown. Such mutual coupling results in a mutual inductance, M. Assuming a negligible back EMF voltage drop, this equivalent circuit can be simplified by Fig. 11(b). In this circuit, the overall equivalent resistance, $R_{\text {eq }}$, is expressed as

$$
\mathrm{R}_{\mathrm{eq}}=\mathrm{R}_{\mathrm{W}}+\left(\frac{\mathrm{R}_{\mathrm{s} \_ \text {loss }} \times \mathrm{R}_{\mathrm{r} \_ \text {loss }}}{\mathrm{R}_{\mathrm{s} \_ \text {loss }}+\mathrm{R}_{\mathrm{r} \_ \text {loss }}}\right) .
$$

where $R_{w}$ is the winding resistance, $R_{s_{\perp} \text { loss }}$ is the stator $H F$ loss-reflected resistance, and $\mathrm{R}_{\mathrm{r} \_ \text {loss }}$ is the rotor loss-reflected resistance. If there are some asymmetric properties in $R_{s_{-} l o s s}$ and $\mathrm{R}_{\mathrm{r} \_ \text {loss }}, \mathrm{R}_{\mathrm{eq}}$ can be modeled as the asymmetric matrix similar to Fig. 1 and (6). The spatial information in $R_{\mathrm{eq}}$ can be used for the self-sensing position estimation.

FEA is performed to investigate the loss distribution in the baseline machine when a HF voltage is superimposed. For the HF voltage selection, a $0.5-\mathrm{V}, 2.5-\mathrm{kHz}$, resulting in the magnitude of $18 \%$ rated current pulsating voltage was injected in the rotor d-axis. Fig. 12 shows the spatial distributions of different loss components after superimposing the HF 


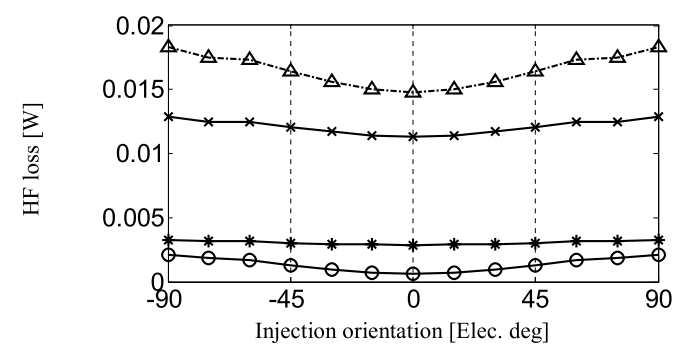

Legend: -O- magnet loss , -x- stator eddy-current loss , -*- stator hysteresis-loss and $-\Delta$ - Total HF loss

Fig. 12. Comparison of HF losses in different components of baseline machine when a d-axis pulsating vector injection is superimposed

voltage. In this analysis, the rotor is controlled at zero speed. $\mathrm{HF}$ losses are calculated when the rotor is locked at different positions. As shown in Fig. 12, the stator eddy-current loss has the highest spatial variation where its loss at $\theta_{\mathrm{e}}=90^{\circ}$ is higher than that at $\theta_{\mathrm{e}}=0^{\circ}$. Similar spatial variation is observed in the magnet eddy-current loss while the variation of stator hysteresis-loss remains at constant. Due to the variation of stator eddy-current loss and magnet loss, the asymmetric resistance appears where the property is $R_{q}>R_{d}$.

It is noted that the asymmetric resistance can appear in standard SPM machines. However, the corresponding resistance-based saliency ratio, $\Delta R / \Sigma R$, is quite low comparing to SPMs with prior saliency design modification. For the baseline machine, the resistance-based saliency ratio, $\Delta R / \Sigma R$, is 0.016 . In addition, the asymmetric resistance is primarily reflected by the eddy-current loss in the stator. As load increases, additional saturation in stator teeth must occur, leading to a change in the eddy-current distribution. As reported in Ref. (7), the increase of load can result in the decrease of $\Delta R / \Sigma R$ and additional spatial angular offset. These non-ideal attributes can make the closed-loop control fail at high load condition. Recently, additional damper windings have been designed in SPM rotors for the position estimation ${ }^{(17)}$. It is expected that the eddy-current in rotor damper windings can be enhanced which could be a possible solution for the closedloop control based on the tracking of asymmetric resistance.

\section{Evaluation of Power-conversion Performance}

In this section, the power-conversion performance of torque output and torque ripple is comparatively evaluated among three SPM machines: baseline, baseline with the iron tooth design and baseline with the tooth bridge height modification. The torque ripple is defined as $\left(T_{\max }-T_{\min }\right) / T_{\text {avg }}$, where $T_{\max }, T_{\min }$ are the maximum and minimum torque over an electric cycle of instantaneous torque, and $\mathrm{T}_{\text {avg }}$ is the arithmetic mean value of the instantaneous torque.

Based on FEA, Fig. 13 shows (a) average torque output, $\mathrm{T}_{\text {avg }}$, and (b) torque ripple versus load in these three SPMs. $\mathrm{T}_{\text {avg }}$ with $100 \%$ rated current is selected as the rated torque. The SPM with the rotor iron tooth design is to achieve $\theta_{\text {th }}$ in Fig. 3(b) equal to $65^{\circ}$. In addition, the SPM with the bridge height modification is to have $\mathrm{d}_{\mathrm{bh}}$ in Fig. 8 equal to $0.6 \mathrm{~mm}$. As shown in (a), the torque output is lowest for the SPM with iron tooth design. The loss of magnet volume for iron tooth design is the primary issue on this reduced torque. By con-

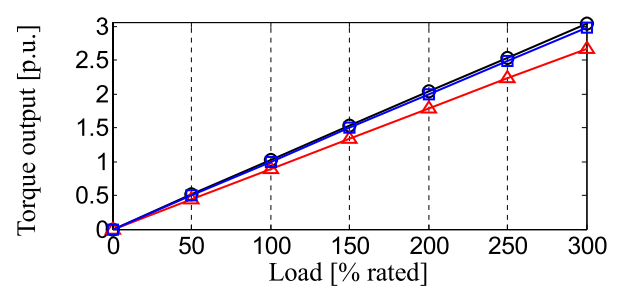

(a) Torque output

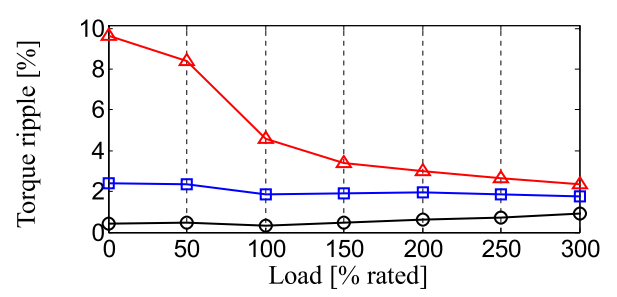

(b) Torque ripple (peak-to-peak per average)

Legend: - O- Baseline , $-\Delta$ - iron tooth design and $-\square$ - tooth bridge height modification

Fig. 13. Comparison of (a) torque output and (b) torque ripple among three different SPM machines

trast, the tooth bridge height design does not affect the condition of magnetizing flux and therefore, the torque output can be maintained. For the comparison of torque ripple in (b), it is found that the increased torque ripple is resulted for the bridge height design. The relatively higher permeance variation is attributed to this increased ripple. However, comparing to the rotor iron tooth design, the influence of torque ripple is significantly reduced especially at partial load condition. This result is concluded that the tooth bridge height design is suited for preserving the power-conversion performance of designed self-sensing SPMs.

\section{Conclusions}

This paper presents the concurrent designs of SPM machines for position estimation and power-conversion. Key conclusions are summarized as follows.

(1) The asymmetric rotor iron tooth design results in the saliency whereby $L_{q}>L_{d}$. The designed saliency is sufficient for the position estimation. However, the reduced torque output and increased torque ripple is the design tradeoff.

(2) The tooth bridge height modulation achieves the reverse saliency whereby $L_{d}>L_{q}$. The designed saliency ratio increases as load increases. In addition, the minor impact on the power-conversion is another important advantage for this saliency design.

(3) The loss-reflected asymmetric resistance appears in standard SPM machines when HF voltage is superimposed. The strong load dependency on the HF eddy-current is the primary limitation.

\section{References}

( 1 ) P.L. Jansen and R.D. Lorenz: "Transducerless position and velocity estimation in induction and salient AC machines", IEEE Trans. on Ind. Appl., Vol.31, pp.240-247 (1995)

( 2 ) M.J. Corley and R.D. Lorenz: "Rotor position and velocity estimation for a salient-pole permanent magnet synchronous machine at standstill and high speeds", IEEE Trans. on Ind. Appl., Vol.34, pp.784-789 (1998)

( 3 ) N. Matsui: "Sensorless PM brushless DC motor drives", IEEE Trans. on Ind. 
Electron., Vol.43, pp.300-308 (1996)

( 4 ) R.W. Hejny and R.D. Lorenz: "Evaluating the Practical Low-Speed Limits for Back-EMF Tracking-Based Sensorless Speed Control Using Drive Stiffness as a Key Metric", IEEE Trans. on Ind. Appl., Vol.47, pp.1337-1343 (2011)

( 5 ) Y.-D. Yoon, S.-K. Sul, S. Morimoto, and K. Ide: "High-Bandwidth Sensorless Algorithm for AC Machines Based on Square-Wave-Type Voltage Injection”, IEEE Trans. on Ind. Appl., Vol.47, pp.1361-1370 (2011)

(6) H. Takashima, M. Tomita, Z. Chen, M. Satoh, S. Doki, and S. Okuma: "Position-and Velocity- Sensorless Control of Cylindrical Brushless DC Motors Driven by Sinusoidal Current at Low Speed Using Eddy Current", IEEJ Trans. IA, Vol.123, pp.762-763 (2003)

( 7 ) S.-C. Yang and R.D. Lorenz: "Surface Permanent Magnet Synchronous Machine Self-Sensing Position Estimation at Low Speed Using Eddy Current Reflected Asymmetric Resistance", IEEE Trans. on Power Electron., Vol.27, pp.2595-2604 (2012)

( 8 ) N. Bianchi and S. Bolognani: "Influence of Rotor Geometry of an IPM Motor on Sensorless Control Feasibility", IEEE Transactions on Ind. Appl., Vol.43, pp.87-96 (2007)

( 9 ) K. Ide, M. Takaki, S. Morimoto, Y. Kawazoe, A. Maemura, and M. Ohto: "Saliency-Based Sensorless Drive of an Adequately Designed IPM Motor for Robot Vehicle Application", IEEJ Trans. IA, Vol.128, pp.379-387 (2008)

(10) K. Akatsu, M. Arimitsu, and S. Wakui: "Design and Control of a Field Intensified Interior Permanent Magnet Synchronous Machine", IEEJ Trans. IA, Vol.126, pp.827-834 (2006)

(11) M.W. Degner and R.D. Lorenz: "Position estimation in induction machines utilizing rotor bar slot harmonics and carrier-frequency signal injection", Trans. On Ind. Appl, Vol.36, pp.736-742 (2000)

(12) I.P. Brown and R.D. Lorenz: "Induction Machine Design Methodology for Self-Sensing: Balancing Saliencies and Power conversion Properties", IEEE Trans. On Ind. Appl., Vol.47, pp.79-87 (2011)

(13) H. Kiyotake, K. Shinohara, and K. Yamamoto: "Rotor Speed Detection Method for Vector Control of Induction Motor without Speed Sensor Utilizing Slot Harmonics", IEEJ Trans. IA, Vol.127, pp.739-746 (2007)

(14) N. Bianchi, S. Bolognani, J. Ji-Hoon, and S. Seung-Ki: "Comparison of PM Motor Structures and Sensorless Control Techniques for Zero-Speed Rotor Position Detection", IEEE Trans. on Power Electron., Vol.22, pp.2466-2475 (2007)

(15) S.-C. Yang, T. Suzuki, R.D. Lorenz, and T.M. Jahns: "Surface permanent magnet synchronous machine design for saliency-tracking self-sensing position estimation at zero and low speeds", IEEE Trans. on Ind. Appl., Vol.47, pp.2013-2116 (2011)

(16) S.-C. Yang and R.D. Lorenz: "Comparison of resistance-based and inductance-based self-sensing control for surface permanent magnet machine using high frequency signal injection", in Energy Conversion Congress and Exposition (ECCE) (2011)
(17) A. Faggion, N. Bianchi, and S. Bolognani: "Ringed-pole permanent magnet synchronous motor for position sensorless drives", IEEE Trans. on Ind. Appl., Vol.47, pp.1759-1766 (2011)

Shih-Chin Yang (Non-member) was born in Taiwan. He received the

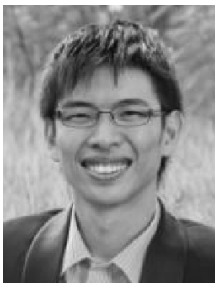
B.S. degree from National Chung Hsing University, Taichung, Taiwan, the M.S. degree from National Taiwan University, Taipei, Taiwan, and the Ph.D. degree from University of Wisconsin-Madison in 2005, 2007 and 2011, respectively. He is currently a Systems Engineer in the Texas Instruments Motor Laboratory, Dallas, TX, where he is responsible for motor control development using low-end microcontroller. His interests include permanent magnet machine design, power electronics and control systems. Dr. Yang was the recipient of the IEEE Industry Applications Society Industrial Drive Committee First Prize Paper Award in 2011.

Robert D. Lorenz (Non-member) received the B.S., M.S., and Ph.D.

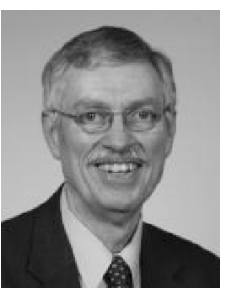
degrees from the University of Wisconsin, Madison, and the M.B.A. degree from the University of Rochester, NY. Since 1984, he has been a member of the faculty of the University of Wisconsin-Madison, where he is the Mead Witter Foundation Consolidated Papers Professor of Controls Engineering in the Department of Mechanical Engineering. He is Co-Director of the Wisconsin Electric Machines and Power Electronics Consortium (WEMPEC). It is the largest industrial research consortium on motor drives and power electronics in the world. Prior to joining the university, he worked 12 years in industry, in Rochester, New York, principally on high performance drives and synchronized motion control. He has authored over 260 published technical papers and is the holder of 24 patents with five more pending. He has won 26 IEEE prize paper awards on power electronics, drives, self-sensing, current regulators, etc. Dr. Lorenz is a Fellow of the IEEE, was IEEE Division II Director for 2005/2006, was the IEEE Industry Applications Society (IAS) President for 2001, a Distinguished Lecturer of the IEEE IAS for 2000/2001. He received the 2003 IEEE IAS Outstanding Achievement award, 2006 EPE PEMC Outstanding Achievement award, and 2011 IEEE IAS Distinguished Service Award. 